RESEARCH ETHICS

\title{
Recruiting donors for autopsy based cancer research
}

\section{J Thombs, N J Borthwick, J L Hungerford, I A Cree}

J Med Ethics 2005;31:360-361. doi: 10.1136/jme.2004.009951

The use of human tissue for scientific research is a highly sensitive issue. A lack of confidence in patient recruitment is one reason for the failure of many studies to be funded and it is important therefore that recruitment procedures are as effective and sympathetic as possible. The authors recruited patients with uveal melanoma into a postmortem study investigating tumour latency in this cancer. Two approaches were used-firstly a direct approach when patients attended clinic and secondly an initial approach by mail followed by telephone contact. In the first year of study the authors had a take up rate of $88.5 \%$, significantly higher than the average rate of $40 \%$ quoted by the National Institute for Clinical Excellence (NICE). Key features are a sympathetic personal approach by experienced oncology nurses, the provision of clear information, and the inclusion of the next of kin in the recruitment procedure.

$\mathrm{R}$ ecruiting sufficient numbers of people willing to donate organs or tissue for clinical research is essential to medical research. Events at both Alder Hey Children's Hospital in Liverpool and Bristol Royal Infirmary surrounding the retention of organs from dead children without parental consent has undoubtedly had an adverse effect on the public's perception of clinical research. The resulting proposed Human Tissue Bill will profoundly influence clinical research in the future. It is all the more important therefore that we develop ethical but effective strategies to optimise recruitment of patients. These should be both sensitive to the patient and next of kin and provide sufficient information to allow informed consent

We set up a research study to investigate latency of metastatic cells in uveal melanoma to determine why some patients' intraocular melanomas spread, while others do not. ${ }^{2}{ }^{3}$ The results will have clear implications for treatment. Because of the difficulty in detecting metastases, this was designed as an autopsy based study in which patients with primary uveal melanoma were asked to donate tissue (liver and lung) after death. We report here the experience of patient recruitment at Moorfields Eye Hospital during the first year of the study.

\section{METHODS AND RESULTS}

The project was reviewed by the Home Office and the Coroners' Association before submission to Cancer Research UK. The project was then submitted to the Multicentre Research Ethics Committee and subsequently to the relevant local research ethics committees for approval. The project follows the requirements of the Royal College of Pathologists ${ }^{4}$ and the MRC guidelines ${ }^{5}$ for the retention of tissue and organs at postmortem examination and the recently proposed Human Tissue Act $^{1}$ An information pack was assembled containing information sheets for the patient and relative, a leaflet explaining the post mortem examination procedure, ${ }^{6}$ and a consent form.
A nurse counsellor attached to the ocular oncology service was employed as the research nurse. Following treatment of the tumour, patients attending for yearly review (2-3 years after treatment) were approached. The nurse ensured the patients met the inclusion criteria and assessed their current emotional wellbeing and support. To limit undue stress and anxiety, only patients who had accepted their diagnosis and treatment well and who were coping with their cancer were approached. Patients were reminded of the rarity of the condition and therefore of their importance to the researchers. The nurse then went through the information pack and answered any questions raised by the patient. The consent form requires signatures from both patient and next of kin who if present were included in all discussions. Following consent a donor card and a copy of the consent form were sent to the participants. Patients who had been discharged in the last five years or who were not due in clinic for some months were approached by mail. The nurse followed this up with a telephone call and an invitation to attend clinic to discuss participation.

In the first 10 months of the study 121 patients were approached. Of those who responded 87 agreed to take part and only 10 declined, a take up rate of $88.5 \%$. Some of those approached by mail had either died already $(n=5)$ or had moved $(n=3)$. Some of the common questions raised during interview and the reasons for declining to take part are shown in box 1. One misconception that often arose was the difference between tissue and organ donation as patients often thought they were required to give the whole organ.

One concern about writing to patients was that it might cause unnecessary anxiety, however out of 78 letters only three individuals expressed any anxiety. One of these individuals was an elderly lady, living alone, who was very upset on receiving the letter. One suggestion to avoid this in future is to contact the patient's GP before any approach is made to the patient. Nevertheless, because of the potential distress to patients by this approach we have now stopped this recruitment procedure.

\section{DISCUSSION}

Recruiting sufficient numbers of donors is a problem facing both clinical studies and organ transplantation. This can be even more of a challenge when patients have rare diseases such as uveal melanoma, where a high take up rate and multicentre-or even international-participation may be required. NICE recently reported that typically only $40 \%$ of those approached agree to take part in clinical trials and that improved communication is the key. ${ }^{7}$ The take up rate in this study of $88.5 \%$ is therefore very encouraging.

The use of expert staff who are experienced in dealing with the issues raised by discussions of death and dying are undoubtedly hugely important. In a recent study, the use of such staff combined with improved information led to a marked increase in the number of organ donors recruited. ${ }^{8}$ Comparison of the effectiveness of nurses and surgeons in recruiting patients has shown nurses to be equally as 


\section{Box 1}

Questions raised during initial interview

- Have I already got liver disease?

- What are the symptoms of liver disease?

- What happens if I do get symptoms?

Reasons for declining to join the study

- Phobia about removal of body parts $(20 \%)$

- Don't want to think about death (30\%)

- Next of kin declined (30\%)

- Thinks the body shouldn't be disturbed (20\%)

effective and more cost effective than surgeons, highlighting the important role of nurses in patient recruitment ${ }^{9}$

The high take up rate in this study shows that if patients are approached in a sensitive manner and are fully informed, then the majority are happy to donate tissue to further research into their condition. We believe that a personal approach by the nurse counsellor was a key factor in the successful recruitment of patients in this study. In addition, the inclusion of the next of kin at all points in the recruitment process is important as they need to be fully informed and aware of the participants' wishes.

\section{Authors' affiliations}

J Thombs, Ocular Oncology Service, Moorfields Eye Hospital, London, UK

N J Borthwick, Pathology Division, Institute of Ophthalmology, London, UK
J L Hungerford, Ocular Oncology Service, Moorfields Eye Hospital, London, UK

I A Cree, Translational Oncology Department, Queen Alexandra Hospital, Cosham, Portsmouth, UK

This project is funded by a grant from Cancer Research UK

There are no financial or other relationships that might lead to a conflict of interest. The manuscript has been read and approved by all the authors and the requirements for authorship have been met.

Correspondence to: Dr N J Borthwick, Pathology Division, Institute of Ophthalmology, 11-43 Bath Street, London ECIV 9EL, UK; n.borthwick@ucl.ac.uk

Received 7 July 2004

Accepted for publication 8 July 2004

\section{REFERENCES}

1 HM Government: Human Tissue Act 2004.

2 Sato T, Babazono A, Sheilds JA, et al. Time to systemic metastases in patients with posterior uveal melanoma. Cancer Invest 1997;15:98-105.

3 Shields JA, Shields CL. Intraocular tumors. Philadelphia: WB Saunders, 1992.

4 Guidelines for the retention of human tissues and organs at post-mortem examination. Royal College of Pathologist 2000.

5 Human tissue and biological samples for use in research-operational and ethical guidelines. Medical Research Council UK, Ethics series 2001

6 HM Government, Department of Health. Simple guide to the post mortem examination procedure, Department of Heath Publications; 29770/A, 2003.

7 Shannon C. NICE Annual Conference Report. BMJ 2003;327:1168.

8 Roth BJ, Sher L, Murray JA, et al. Cadaveric organ recruitment at Los Angeles County Hospital: improvement after formation of a structured clinical educational and administrative service. Clin Transplant 2003;17(suppl 9):52-7.

9 Donovan JL, Peters TJ, Noble S, et al. Who can best recruit to randomized trials? Randomized trial comparing surgeons and nurses recruiting patients to a trial of treatments for localized prostate cancer (the ProtecT study). J Clin Epidemiol 2003;56:605-9 